\title{
Visualisasi Gelombang Sudut dalam Koordinat Bola untuk Potensial Eckart Plus Scarf dengan Pendekatan Analisis Persamaan Schrodinger Metode Nikiforov Uvarov Menggunakan Matrix Laboratory
}

\author{
Visualization of Angular Wave in Spherical Coordinate for Eckart Plus \\ Scarf Potential with Schroodinger Equation Analysis Approach of \\ Nikiforov-Uvarov Using Matrix Laboratory
}

\author{
Luqman Hakim $^{1 *}$, Suparmi ${ }^{2}$, Cari $^{2}$

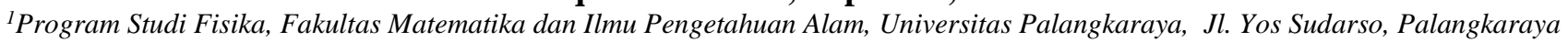 \\ 73112 A, Indonesia \\ ${ }_{2}^{2}$ Program Pascasarjana, Universitas Sebelas Maret,Surakarta, Jl. Ir. Sutami 36A Kentingan, Surakarta 57126, Indonesia
}

*Alamat email: luqman_h@mipa.upr.ac.id

\begin{abstract}
Abstrak - Penelitian pendekatan analisis persamaan Schrodinger bertujuan untuk menentukan fungsi gelombang sudut untuk potensial Eckart plus Scarf dengan metode Nikiforov-Uvarov. Metode Nikiforov-Uvarov merupakan metode penyelesaian persamaan diferensial orde kedua dengan mengubah persamaan tersebut menjadi persamaan perantara hipergeometrik dengan metode pemisahan variable melalui substitusi variabel yang sesuai. Hasil analisis yang fungsi gelombang sudut yang selanjutnya divisualisasikan dengan menggunakan pemrograman Matrix Laboratory 2013. Hasil visualisasi menunjukkan bahwa semakin meningkat bilangan kuantum, gelombang sudut semaikin banyak. Hal ini menunjukkan bahwa fungssi gelombang sudut mengalami degenerasi. Visualisasi fungsi gelombang sudut yang terbentuk mendiskripsikan gerakan partikel mengelilingi inti.
\end{abstract}

Kata kunci: persamaan schrodinger dimensi-d, potensial eckart plus scarf, metode nikiforov-uvarov, matrix laboratory 2013,fungsi gelombang sudut

Abstract - Schrodinger's equation analysis research approach aims to determine the angular wave function for the Eckart plus Scarf potential with the Nikiforov-Uvarov method. The Nikiforov-Uvarov method is a method of solving a secondorder differential equation by converting the equation into a hypergeometric intermediate equation with the variable separation method through the appropriate variable substitution. The results of the analysis of the angular wave function which is then visualized using the Matrix Laboratory 2013 programming. Visualization results show that as quantum numbers increase, angular waves are more numerous. This shows that the function of the angular wave degenerates. Visualization of the formed angular wave function describes the motion of the particles around the nucleus.

Keywords: Schrodinger-D Dimension Equation, Eckart Potential plus Scarf, Nikiforov-Uvarov Method, Matrix Laboratory 2013, Angular wave function

(C) 2019 Jurnal Jejaring Matematika dan Sains. This work is licensed under a CC BY-NC 4.0

Sejarah Artikel

Diterima : 16 November 2019

Disetujui : 24 Desember 2019

\section{PENDAHULUAN}

Mekanika kuantum merupakan dasar untuk pemahaman tentang fenomena fisik pada skala mikroskopik[1]. Mekanika kuantum selalu menggunakan pendekatan yang berbeda untuk menentukan besaran yang terkait dengan gerak partikel yaitu menggunakan fungsi gelombang untuk merpresentasikan dinamika partikel yang bergerak yang diperoleh dari penyelesaian persamaan Schrödinger dari partikel yang berkaitan. Persamaan gerak partikel dapat diselesaikan mengunakan persamaan Schrodinger, persamaan Klein-Gordon dan persamaan Dirac[2]

Beberapa metode dapat digunakan untuk menyelesaikan persamaan Schroodinger, antara lain Super Simetry (SUSY), confluence hypergeometry, Romanovsky, dan Nikiforov-Uvarov[3]. Potensial dalam kuantum menggambarkan dinamika partikel di mekanika kuantum[4]. Beberapa contoh potensial dalam mekanika kuantum antara lain osilator harmonic, potensial Coloumb, Rosen Morse, Manning-Rosen, Scarf, Poschl Teller Eckart dan lain-lain[5] Penelitian ini merupakan penelitian analisis persamaan Schrodinger dimensi-D yang 
bertujuan untuk memvisualisasi gelombang sudut dalam koordinat bola untuk potensial non sentral Eckart plus Scarf.

Persamaan Schrodinger dimensi-D didasari dengan penggunaan koordinat polar D-dimensi dengan hypersperical coordinates $r$ dan $\theta_{b}$. Hubungan antara koordinat kartesian $x_{i}$ dengan hypersperical coordinates $r$ dan $\theta_{b}$ dalam dimensi-D didefinisikan sebagai [6] :

$$
\begin{aligned}
& x_{1}=r \cos \theta_{1} \sin \theta_{1} \ldots \ldots \ldots \sin \theta_{D-1,} \\
& x_{2}=r \cos \theta_{2} \sin \theta_{2} \ldots \ldots \ldots \sin \theta_{D-1,} \\
& x_{b}=r \cos \theta_{b-1} \sin \theta_{b} \ldots \ldots \ldots \sin \theta_{D-1,} \\
& x_{D}=r \cos \theta_{D-1}
\end{aligned}
$$

dimana $b \in[3, D-1]$. Penjumlahan masing-masing Persamaan (1) diperoleh :

$$
r^{2}=\sum_{i=1}^{D} x_{i}^{2}
$$

$r$ merupakan radius dimensi-D dengan komponen koordinat bola. Operator Laplacian dalam koordinat polar didefinisikan sebagai :

$$
\nabla_{D}^{2}=\frac{1}{h} \sum_{k=0}^{D-1} \frac{\partial}{\partial \theta_{k}}\left(\frac{h}{h_{k}^{2}} \frac{\partial}{\partial \theta_{k}}\right)
$$

Hubungan antara koordinat kartesian $x_{i}$ dengan hypersperical coordinates $r$ dan $\theta_{b}$ dalam dimensi-D. Persamaan Schrodinger untuk dimensi-D didefinisikan sebagai [7]:

$$
-\frac{\hbar^{2}}{2 m} \nabla_{D}^{2} \psi_{\left(r, \Omega_{\mathrm{D}}\right)}+V \psi_{\left(r, \Omega_{\mathrm{D}}\right)}=E \psi_{\left(r, \Omega_{\mathrm{D}}\right)}
$$

dengan $\nabla_{D}^{2}$ merupakan operator Laplacian dalam dimensiD, yaitu :

$$
\nabla_{D}^{2}=\frac{1}{r^{D-1}} \frac{\partial}{\partial r}\left(r^{D-1} \frac{\partial}{\partial r}\right)-\frac{L_{D-1}^{2}}{r^{2}}
$$

Nilai $L_{D-1}^{2}=\Lambda_{D}^{2}\left(\Omega_{D}\right) \quad$ merupakan operator momentum anguler dimensi-D, yaitu:

$$
\begin{aligned}
& \Lambda_{D}^{2}\left(\Omega_{D}\right)=L_{k}^{2}=\sum_{a<b}^{k+1} L_{a b}^{2}= \\
& -\left\{\frac{1}{\sin ^{k-1} \theta_{k}} \frac{\partial}{\partial \theta_{k}}\left(\sin ^{k-1} \theta_{k} \frac{\partial}{\partial \theta_{k}}\right)-\frac{L_{k-1}^{2}}{\sin ^{2} \theta_{k}}\right\}
\end{aligned}
$$

Penyelesaian Persamaan Schrodinger dimensi -D dengan melakukan separasi variabel dengan memisalkan :

$$
\psi_{n l m}\left(r, \Omega_{D}\right)=R_{n l}(r) Y_{l}^{m}\left(\Omega_{D}\right)
$$

Dengan $R_{n l}$ adalah bagian radial dari Persamaan (7) dan $Y_{l}^{m}$ adalah bagian sudutnya. Persamaan Schrodinger dimensi-D bagian sudut harus memenuhi Persamaan nilai eigen:

$$
\Lambda_{D}^{2} Y_{l}^{m}\left(\Omega_{D}\right)=l(l+D-2) Y_{l}^{m}\left(\Omega_{D}\right)
$$

Dengan mensubsitusikan Persamaan (8) ke dalam Persamaan (4) melalui sparasi variabel pada Persamaan (4), maka diperoleh Persamaan :

$$
\begin{aligned}
& \frac{1}{r^{D-1}} \frac{\partial}{\partial r}\left(r^{D-1} \frac{\partial R_{n l}(r)}{\partial r}\right)+\frac{2 m}{\hbar^{2}}\left[E_{n l}+\frac{l(l+D-2)}{r^{2}}-V(r)\right]=0 \text { (9) } \\
& \Lambda_{D}^{2}\left(\Omega_{D}\right) Y_{l}^{m}\left(\Omega_{D}\right)+V\left(\Omega_{D}\right) Y_{l}^{m}\left(\Omega_{D}\right)=l(l+D-2) Y_{l}^{m}\left(\Omega_{D}\right)
\end{aligned}
$$

Persamaan (9) dan Persamaan (10) merupakan Persamaan bagian radial dan Persamaan bagian sudut untuk dimensi-D.

Potensial Eckart sering digunakan untuk memperkirakan koreksi tunneling mekanika kuantum untuk konstanta laju kimia teoritis yang ditentukan[8]. Potensial Scarf adalah merupakan potensial yang menggabarkan suatu partikel yang tersusun secara periodik, seperti kristal dalam zat padat[9]. Kombinasi potensial Eckart dan potensial Scarf secara matematis dapat dituliskan sebagai:

$$
\begin{aligned}
& V\left(r, \Omega_{D}\right)=\frac{\hbar^{2}}{2 m}\left(\frac{V_{0} e^{-r / a}}{\left(1-e^{-r / a}\right)^{2}}-\frac{V_{1}\left(1+e^{-r / a}\right)}{\left(1-e^{-r / a}\right)}\right)+ \\
& \frac{\hbar^{2}}{2 m r^{2}}\left(\frac{b^{2}+a(a-1)}{\sin ^{2} \theta}-\frac{2 b\left(a-\frac{1}{2}\right) \cos \theta}{\sin ^{2} \theta}\right)
\end{aligned}
$$

dimana $0<r / \alpha<\sim$ dan $V_{0}<V_{1}$. Nilai $V_{0}$ maupun $V_{1}$ lebih besar dari nol, a dan b adalah parameter dengan orde fm.

Matrix Laboratory (MATLAB) merupakan sebuah bahasa dengan kinerja tinggi untuk komputasi masalah teknik. MATLAB mengintegrasikan komputasi, visualisasi, dan pemrograman dalam suatu model yang sangat mudah untuk pakai dimana masalah-masalah dan penyelesaiannya diekspresikan dalam notasi matematika yang familiar. Penggunaan MATLAB meliputi matematika dan komputasi, algoritma, akuisisi, pemodelan dan visualisasi[10].

\section{METODE PENELITIAN}

Penelitian ini menggunakan Pendekatan dengan Metode Nikiforov-Uvarov. Metode ini didasari pereduksian Persamaan diferensial orde dua menjadi Persamaan umum diferensial orde dua tipe Hipergeometri. Persamaan deferensial Hipergeometri, yang dapat diselesaikan dengan metode Nikiforov-Uvarov memiliki bentuk [11]:

$$
\frac{\partial^{2} \psi(s)}{\partial s^{2}}+\frac{\bar{\tau}(s)}{\sigma(s)} \frac{\partial \psi(s)}{\partial s}+\frac{\bar{\sigma}(s)}{\sigma^{2}} \psi(s)=0
$$

dimana $\sigma(s)$ dan $\bar{\sigma}(s)$ merupakan polinomial berderajat dua, dan $\bar{\tau}(s)$ merupakan polinomial berderajat satu. Persamaan (12) dapat diselesaikan dengan pemisahan variabel yaitu :

$$
\psi=\phi(s) y(s)
$$

Persamaan (12) dapat direduksi dengan mensubsitusikan nilai $\psi$ pada persamaan (13), sehingga diperoleh:

$$
\sigma(s) \frac{\partial^{2} \psi(s)}{\partial s^{2}}+\grave{\tau}(s) \frac{\partial \psi(s)}{\partial s}+\lambda \psi(s)=0
$$

Persamaan (14) yang ekuivalen dengan Persamaan (12). Parameter-parameter dalam metode Nikivorov Uvarov, yaitu $\pi$ dan parameter $\lambda$ didefinisikan sebagai:

$$
\begin{aligned}
& \pi=\left(\frac{\sigma^{\prime}-\bar{\tau}}{2}\right) \pm \sqrt{\left(\frac{\sigma^{\prime}-\bar{\tau}}{2}\right)^{2}-\bar{\sigma}+j \sigma} \\
& \lambda=j+\pi^{\prime}(s)
\end{aligned}
$$


Harga j pada Persamaan (16) dapat diperoleh dari kondisi bahwa pernyataan kuadrat dibawah akar merupakan kuadrat sempurna dari polinomial derajat satu, sehingga diskriminan dibawah akar harus nol.

Eigen nilai dari persamaan (14) dinyatakan sebagai:

$$
\lambda=\lambda_{n}=-n \tau^{\prime}-\frac{n(n-1)}{2} \sigma^{\prime \prime}
$$

Dengan $\mathrm{n}=0,1,2 \ldots$ dan

$$
\tau=\overleftarrow{\tau}+2 \pi
$$

Untuk mendapatkan energi eigen nilai dan fungsi eigen yang terkait, diperlukan kondisi $\tau^{\prime}<0$. Solusi bagian pertama dari fungsi gelombang diperoleh dengan persamaan:

$$
\frac{\phi^{\prime}}{\phi}=\frac{\pi}{\sigma}
$$

Solusi bagian kedua fungsi gelombang $y_{n}(s)$ yang bersesuaian dengan relasi Rodrigues ditunjukan oleh persamaan berikut [12]:

$$
y_{n}(s)=\frac{C_{n}}{\rho(s)} \frac{d^{n}}{d z^{n}}\left(\sigma^{n}(s) \rho(s)\right)
$$

dimana $C_{n}$ merupakan konstanta normalisasi, dan fungsi bobot $\rho(s)$ harus tergantung pada kondisi

$$
\frac{\partial(\sigma \rho)}{\partial s}=\tau(s) \rho(s)
$$

Alat yang digunakan dalam penelitian ini adalah Komputer dengan prosesor AMD A6, 16 GB Memory dengan software untuk visualisai gelombang sudut adalah Matlab 2013.

\section{HASIL DAN PEMBAHASAN}

Penyelesaian Bilangan Kuantum Orbital bagaian sudut dari kombinasi potensial Eckart Scarf dapat dilakukan dengan metode Nikiforov Uvarov. Potensial Eckart plus Scarf jika disubsitusi dalam persamaan Schrodinger dimensi-D, pemisahan variabel bagian sudut diperoleh persamaan:

$\frac{1}{Y\left(\Omega_{D}\right)} \Lambda_{D}^{2}\left(\Omega_{D}\right) Y\left(\Omega_{D}\right)+\left(\frac{b^{2}+a(a-1)}{\sin ^{2} \Omega_{D}}-\frac{2 b\left(a-\frac{1}{2}\right) \cos \Omega_{D}}{\sin ^{2} \Omega_{D}}\right)=$

$l(l+D-2)$

Solusi dari Persamaan (22) adalah persamaan gelombang bagian sudut dengan bilangan kuantum $l_{1}, l_{2}$, $l_{3}, \ldots, l_{D-1}$. Dengan memisalkan

$$
Y_{l_{1} \ldots l_{D-2}}^{(l)}\left(\Omega_{D}\right)=\Phi\left(\theta_{1}=\varphi\right) \mathrm{G}\left(\theta_{2} \ldots \theta_{D-1}\right)
$$

Persamaan (23) dapat ditulis sebagai :

$$
L_{D}^{2} \Phi G+\left(\frac{b^{2}+a(a-1)}{\sin ^{2} \theta_{k}}-\frac{2 b\left(a-\frac{1}{2}\right) \cos \theta_{k}}{\sin ^{2} \theta_{k}}-l(l+D-\right.
$$

2)) $\Phi G=0$

Jika persamaan (24) dibagi $\Phi \mathrm{G}$, maka diperoleh:

$$
\begin{aligned}
& \frac{1}{\mathrm{G}} \frac{1}{\sin ^{k-1} \theta_{k}}\left(\sin ^{k-1} \theta_{k} \frac{\partial \mathrm{G}}{\partial \theta_{k}}\right)-\frac{1}{G} \frac{1}{\sin ^{2} \theta_{k}} L_{k-1}^{2} \mathrm{G}- \\
& \left(\frac{b^{2}+a(a-1)}{\sin ^{2} \theta_{k}}-\frac{2 b\left(a-\frac{1}{2}\right) \cos \theta_{k}}{\sin ^{2} \theta_{k}}-l(l+D-2)\right)= \\
& -\frac{1}{\Phi} \frac{\partial^{2} \Phi}{\partial \theta_{1}}=L_{k}^{2}
\end{aligned}
$$

Dengan eigenvalue $L_{j}^{2}$

$$
\begin{aligned}
& L_{1}^{2} Y_{l_{1}}^{l}\left(\Omega_{D}\right)=m^{2} Y_{l_{1}}^{l}\left(\Omega_{D}\right) \\
& L_{j}^{2} Y_{l_{1}, \ldots l_{D-2}}^{l}\left(\Omega_{D}\right)=l_{j}\left(l_{j}+j-1\right) Y_{l_{1}, \ldots l_{D-2}}^{l}\left(\Omega_{D}\right)
\end{aligned}
$$

Fungsi gelombang bagian azimuth pada adalah:

$$
-\frac{1}{\Phi} \frac{\partial^{2} \Phi}{\partial \theta_{1}}=L_{k}^{2}
$$

Untuk nilai $k=1$, dengan $\theta_{1}=\varphi$ dikalikan dengan $\Phi$, maka diperoleh :

$$
\begin{gathered}
\frac{\partial^{2} \Phi}{\partial \varphi}+L_{1}^{2} \Phi=0 \\
\frac{\partial^{2} \Phi}{\partial \varphi}+m^{2} \Phi=0
\end{gathered}
$$

Persamaan (30) merupakan persamaan azimuth yang menggambarkan rotasi elektron terhadap sumbu $z$. Rentangan sumbu rotasi di sekitar sumbu $z$ ini adalah 0 $2 \pi$ sehingga bentuk penyelesaiannya merupakan fungsi sinusoidal yang bersifat periodik. Solusi umum dari Persamaan (4.13) adalah :

$\Phi=A e^{i m \varphi}+B e^{-i m \varphi}$

Solusi dari persamaan gelombang bagian azimuth adalah:

$$
\Phi=\frac{1}{\sqrt{2 \pi}} e^{i m \varphi}
$$

Pada bagian polar persamaan dapat ditulis sebagai :

$$
\begin{gathered}
\frac{1}{\sin ^{k-1} \theta_{k}}\left(\sin ^{k-1} \theta_{k} \frac{\partial \mathrm{G}}{\partial \theta_{k}}\right)-\frac{1}{\sin ^{2} \theta_{k}} L_{k-1}^{2} \mathrm{G}+ \\
L_{k}^{2} \mathrm{G}-\left(\frac{b^{2}+a(a-1)}{\sin ^{2} \theta_{k}}-\frac{2 b\left(a-\frac{1}{2}\right) \cos \theta_{k}}{\sin ^{2} \theta_{k}}\right) \mathrm{G}=0
\end{gathered}
$$

Persamaan (33) dipisahkan menjadi 2 bagian, yaitu :

1. Pada kondisi $k=2,3, \ldots, D-2$

Pada kondisi ini, berdasarkan Persamaan (33) dan nilai eigen fungsi $\quad L_{j}^{2} Y_{l_{1}, \ldots l_{D-2}}^{l}\left(\Omega_{D}\right)=l_{j}\left(l_{j}+j-\right.$ 1) $Y_{l_{1}, \ldots l_{D-2}}^{l}\left(\Omega_{D}\right)$, maka :

$\frac{1}{\sin ^{k-1} \theta_{k}}\left(\sin ^{k-1} \theta_{k} \frac{\partial \mathrm{G}}{\partial \theta_{k}}\right)-\frac{l_{k-1}\left(l_{k-1}+k-2\right)}{\sin ^{2} \theta_{k}} \mathrm{G}+l_{k}\left(l_{k}+k-\right.$

1) $\mathrm{G}+\left(\frac{b^{2}+a(a-1)}{\sin ^{2} \theta_{k}}-\frac{2 b\left(a-\frac{1}{2}\right) \cos \theta_{k}}{\sin ^{2} \theta_{k}}\right) \mathrm{G}=0$

2. Pada kondisi $k=D-1$

Pada kondisi ini, berdasarkan Persamaan (33) dan nilai eigen fungsi $L_{j}^{2} Y_{l_{1}, \ldots l_{D-2}}^{l}\left(\Omega_{D}\right)=l_{j}\left(l_{j}+j-\right.$ 1) $Y_{l_{1}, \ldots l_{D-2}}^{l}\left(\Omega_{D}\right)$, maka :

$$
\begin{aligned}
& \frac{1}{\sin ^{D-2} \theta_{D-1}}\left(\sin ^{D-2} \theta_{D-1} \frac{\partial \mathrm{G}}{\partial \theta_{D-1}}\right)- \\
& \frac{l_{D-2}\left(l_{D-2}+D-3\right)}{\sin ^{2} \theta_{D-1}} \mathrm{G}+l_{D-1}\left(l_{D-1}+D-2\right) \mathrm{G}- \\
& \left(\frac{b^{2}+a(a-1)}{\sin ^{2} \theta_{D-1}}-\frac{2 b\left(a-\frac{1}{2}\right) \cos \theta_{D-1}}{\sin ^{2} \theta_{D-1}}\right) \mathrm{G}=0
\end{aligned}
$$

Mengingat nilai eigen dari Persamaan (33), maka $L_{D-1}^{2}=\left(l_{D-1}+D-2\right)$, dengan demikian nilai $l(l+D-$ 2) termasuk dalam variabel $L_{k}^{2}$.

Penyelesaian bagian sudut dari potensial Eckart plus Scarf dimensi-D pada kondisi $k=2,3, \ldots, D-2$ adalah dengan memisalkan $A_{k}=l_{k}\left(l_{k}+k-1\right)$ dan $A_{k-1}=$ $l_{k-1}\left(l_{k-1}+k-2\right)$, maka diperoleh:

$$
\begin{aligned}
& \frac{\partial^{2} \mathrm{G}}{\partial \theta_{k}^{2}}+(k-1) \cot \theta_{k} \frac{\partial \mathrm{G}}{\partial \theta_{k}}-\left(\frac{A_{k-1}}{\sin ^{2} \theta_{k}}-A_{k}\right) \mathrm{G}- \\
& \left(\frac{b^{2}+a(a-1)}{\sin ^{2} \theta_{k}}-\frac{2 b\left(a-\frac{1}{2}\right) \cos \theta_{k}}{\sin ^{2} \theta_{k}}\right) \mathrm{G}=0
\end{aligned}
$$

Persamaan (36) direduksi menjadi persamaan diferensial orde 2 dengan pemisalan $\cos \theta_{k}=s$, maka diperoleh :

$$
\begin{aligned}
& \frac{d^{2}}{d s^{2}} G-\frac{k s}{\left(1-s^{2}\right)} \frac{d}{d s} G-\left\{\frac{b^{2}+a(a-1)}{\left(1-s^{2}\right)^{2}}-\frac{2 b\left(a-\frac{1}{2}\right) s}{\left(1-s^{2}\right)^{2}}+\right. \\
& \left.\frac{A_{k-1}}{\left(1-s^{2}\right)^{2}}-\frac{A_{k}\left(1-s^{2}\right)}{\left(1-s^{2}\right)^{2}}\right\} G=0
\end{aligned}
$$

Persamaan (37) merupakan persamaan diferensial orde dua hipergeometri, sehingga diperoleh hubungan : 
$\bar{\tau}=-k s$

$\sigma=\left(1-s^{2}\right)$ maka $\sigma^{\prime}=-2 s$

$\bar{\sigma}=-\left\{b^{2}+a(a-1)-2 b\left(a-\frac{1}{2}\right) s+A_{k-1}-\right.$

$\left.A_{k}\left(1-s^{2}\right)\right\}$

Dan nilai parameter $\pi=\left(\frac{(k-2) s}{2}\right) \pm$

$$
\sqrt{\begin{array}{c}
\left(\frac{(k-2)^{2}}{4}+A_{k}-j\right) s^{2}-2 b\left(a-\frac{1}{2}\right) s+b^{2}+a(a-1) \\
+A_{k-1}-A_{k}+j-\frac{(k-2)^{2}}{4}+\frac{(k-2)^{2}}{4}
\end{array}}
$$

Dengan memisalkan nilai $p^{2}=\frac{(k-2)^{2}}{4}+A_{k}-j \quad$, maka diperoleh :

$$
\pi=\frac{((k-2) s)}{2} \pm p\left(s+\frac{-2 b\left(a-\frac{1}{2}\right)}{2 p^{2}}\right)
$$

Selanjutnya dilakukan perhitungan untuk menentukan nilai $\tau$ dan $\lambda$ pada kondisi umum dengan mengambil nilai $\pi$ negatif (keadaan bound state).

$$
\begin{aligned}
& \tau=-2 s-p\left(s+\frac{-2 b\left(a-\frac{1}{2}\right)}{2 p^{2}}\right) \\
& \lambda_{1}=\lambda_{2}=\frac{(k-2)^{2}}{4}+A_{k}-p^{2}+p-\frac{(k-2)}{2}
\end{aligned}
$$

Penyelesaian bilangan kuantum orbital bagian sudut dari potensial Eckart plus Scarfuntuk kondisi $k=D-1$ pada Persamaan

$$
\begin{aligned}
& \frac{1}{\sin ^{D-2} \theta_{D-1}}\left(\sin ^{D-2} \theta_{D-1} \frac{\partial \mathrm{G}}{\partial \theta_{D-1}}\right)- \\
& \frac{l_{D-2}\left(l_{D-2}+D-3\right)}{\sin ^{2} \theta_{D-1}} \mathrm{G}+l_{D-1}\left(l_{D-1}+D-2\right) \mathrm{G}- \\
& \left(\frac{b^{2}+a(a-1)}{\sin ^{2} \theta_{D-1}}-\frac{2 b\left(a-\frac{1}{2}\right) \cos \theta_{D-1}}{\sin ^{2} \theta_{D-1}}\right) \mathrm{G}=0
\end{aligned}
$$

Dengan memisalkan $A_{D-1}=l_{D-1}\left(l_{D-1}+D-2\right)$ dan $A_{D-2}=l_{D-2}\left(l_{D-2}+D-3\right)$, maka diperoleh:

$$
\begin{aligned}
& \frac{\partial^{2} \mathrm{G}}{\partial \theta_{D-1}^{2}}+(D-2) \frac{\cos \theta_{D-1}}{\sin \theta_{D-1}} \frac{\partial \mathrm{G}}{\partial \theta_{D-1}}-\left(\frac{A_{D-2}}{\sin ^{2} \theta_{D-1}}-\right. \\
& \left.A_{D-1}\right) \mathrm{G}-\left(\frac{b^{2}+a(a-1)}{\sin ^{2} \theta_{D-1}}-\frac{2 b\left(a-\frac{1}{2}\right) \cos \theta_{D-1}}{\sin ^{2} \theta_{D-1}}\right) \mathrm{G}=0
\end{aligned}
$$

Persamaan (45) direduksi menjadi Persamaan diferensial orde 2 dengan pemisalan $\cos \theta_{D-1}=s$ sehingga diperoleh:

$$
\begin{aligned}
& \frac{d^{2}}{d s^{2}} G-\frac{(D-1) s}{\left(1-s^{2}\right)} \frac{d}{d s} G-\left\{\frac{b^{2}+a(a-1)}{\left(1-s^{2}\right)^{2}}-\frac{2 b\left(a-\frac{1}{2}\right) s}{\left(1-s^{2}\right)^{2}}+\frac{A_{D-2}}{\left(1-s^{2}\right)^{2}}-\right. \\
& \left.\frac{A_{D-1}\left(1-s^{2}\right)}{\left(1-s^{2}\right)^{2}}\right\} G=0
\end{aligned}
$$

Persamaan (46) merupakan persamaan diferensial orde dua hipergeometri, sehingga diperoleh hubungan :

$$
\begin{aligned}
& \bar{\tau}=-(D-1) s \\
& \sigma=\left(1-s^{2}\right) \text { maka } \sigma^{\prime}=-2 s \\
& \bar{\sigma}=-\left\{b^{2}+a(a-1)-2 b\left(a-\frac{1}{2}\right) s+A_{D-2}-\right. \\
& \left.A_{D-1}\left(1-s^{2}\right)\right\}
\end{aligned}
$$

dengan nilai parameter

$$
\begin{gathered}
\pi=\left(\frac{(D-3) s}{2}\right) \pm \\
\sqrt{\left(\frac{(D-3)^{2}}{4}+A_{D-1}-j\right) s^{2}-2 b\left(a-\frac{1}{2}\right) s+b^{2}+a(a-1)} \\
\quad+A_{D-2}+\frac{(D-3)^{2}}{4}-\frac{(D-3)^{2}}{4}-A_{D-1}+j
\end{gathered}
$$

Dengan memisalkan $p^{2}=\frac{(D-3)^{2}}{4}+A_{D-1}-j$, maka diperoleh:

$$
\pi=\left(\frac{(D-3) s}{2}\right) \pm p\left(s+\frac{-2 b\left(a-\frac{1}{2}\right)}{2 p^{2}}\right)
$$

Selanjutnya dilakukan perhitungan untuk menentukan nilai $\tau$ dan $\lambda$ pada kondisi umum dengan mengambil nilai $\pi$ negatif (keadaan bound state).

$$
\lambda=\frac{(D-3)^{2}}{4}+A_{D-1}-p^{2}+\frac{(D-3)}{2}-p
$$

Persamaan bilangan kuantum orbital pada kondisi khusus, merupakan reduksi dari persamaan bilangan kuantum orbital pada kondisi umum $k=2,3, \ldots, D-2$ dan $k=D-1$. Hal ini menunjukkan bahwa bilangan kuantum orbital kondisi umum untuk $k=2,3, \ldots, D-2$ dan $k=D-1$ bernilai sama.

Tabel 1. Fungsi Gelombang Sudut Kombinasi Potensial Eckart plus Scarf dengan Variasi $n_{l}$

\begin{tabular}{cccccc}
$\boldsymbol{n}_{\boldsymbol{l}}$ & $\boldsymbol{m}$ & $\boldsymbol{a}(\boldsymbol{f m})$ & $\boldsymbol{b}(\boldsymbol{f} \boldsymbol{m})$ & $\boldsymbol{l}$ & \multicolumn{1}{c}{ Persamaan gelombang $(\boldsymbol{G}(\cos \boldsymbol{\theta}))$} \\
\hline 0 & 1 & 2 & 2 & 2,303 & $G(\cos \theta)=\left(\sin ^{2} \theta\right)^{1,151}(1+\cos \theta)^{0,651}(1-\cos \theta)^{-0,651}$ \\
1 & 1 & 2 & 2 & 3,303 & $\begin{array}{l}G(\cos \theta)=\left(\sin ^{2} \theta\right)^{1,151}(1+\cos \theta)^{0,651}(1- \\
\cos \theta)^{-0,651} x(-0,5)\{[-2,000(1+\cos \theta)+4.606(1-\cos \theta)]\} \\
G(\cos \theta)=\left(\sin ^{2} \theta\right)^{1,151}(1+\cos \theta)^{0,651}(1-\cos \theta)^{-0,651} x 0,125\{6,000(1+ \\
\left.\cos \theta)^{2}-33.633(1+\cos \theta)(1-\cos \theta)+25,817(1-\cos \theta)^{2}\right\}\end{array}$ \\
3 & 1 & 2 & 2 & 4,303 & $\begin{array}{l}G(\cos \theta)=\left(\sin ^{2} \theta\right)^{1,151}(1+\cos \theta)^{0,651}(1- \\
\cos \theta)^{-0,651} x(-0,02083)\left\{-24,000(1+\cos \theta)^{3}+237,800(1-\right. \\
\left.\cos \theta)(1+\cos \theta)^{2}-444.333(1+\cos \theta)(1-\cos \theta)^{2}+170,533(1-\cos \theta)^{3}\right\}\end{array}$ \\
\hline
\end{tabular}


Tabel 2. Fungsi Gelombang Sudut Kombinasi Potensial Eckart Plus Scarf Akibat Pengaruh Pergerakan Parameter potensial

\begin{tabular}{cccccl}
\hline $\boldsymbol{n}_{\boldsymbol{l}}$ & $\boldsymbol{m}$ & $\boldsymbol{a}(\boldsymbol{f m})$ & $\boldsymbol{b}(\boldsymbol{f m})$ & $\boldsymbol{l}$ & \multicolumn{1}{c}{ Persamaan gelombang $(\boldsymbol{G}(\cos \boldsymbol{\theta}))$} \\
\hline 2 & 1 & 0 & 0 & 3,00 & $\begin{array}{l}G(\cos \theta)=\left(\sin ^{2} \theta\right)^{0,500}(1+\cos \theta)^{0,00}(1-\cos \theta)^{0,00} x 0,125\{6,00(1+ \\
\left.\cos \theta)^{2}-18,00(1+\cos \theta)(1-\cos \theta)+6,00(1-\cos \theta)^{2}\right\}\end{array}$ \\
2 & 1 & 2 & 2 & 4,303 & $\begin{array}{l}G(\cos \theta)=\left(\sin ^{2} \theta\right)^{1,151}(1+\cos \theta)^{0,651}(1-\cos \theta)^{-0,651} x 0,125\{6,000(1+ \\
\left.\cos \theta)^{2}-33,633(1+\cos \theta)(1-\cos \theta)+25,817(1-\cos \theta)^{2}\right\} \\
G(\cos \theta)=\left(\sin ^{2} \theta\right)^{2,137}(1+\cos \theta)^{1,637}(1-\cos \theta)^{1,637} x 0,125\{6,000(1+ \\
\left.\cos \theta)^{2}-57,299(1+\cos \theta)(1-\cos \theta)+81,650(1-\cos \theta)^{2}\right\}\end{array}$ \\
2 & 1 & 4 & 4 & 6,275 &
\end{tabular}

Berdasar Tabel 1, selanjutnya dilakukan visualisasi gelombang sudut menggunakan software Matlab 2013. Alur visualisasi gelombang sudut dengan menggunakan program Matlab adalah sebagai berikut (Gambar 2).

Penetuan definisi variabel theta dari 0 sampai 2 pi dan -pi sampai pi, menentukan parameter pada potensial, menuliskan persamaan Gelombang sudut berdasar Tabel 1, plot gambar 3 dimensi (3D) dan 2 dimensi (2D). Hasil visualisasi untuk variasi bilangan kuantum $n_{l}$ terlihat pada Gambar1.

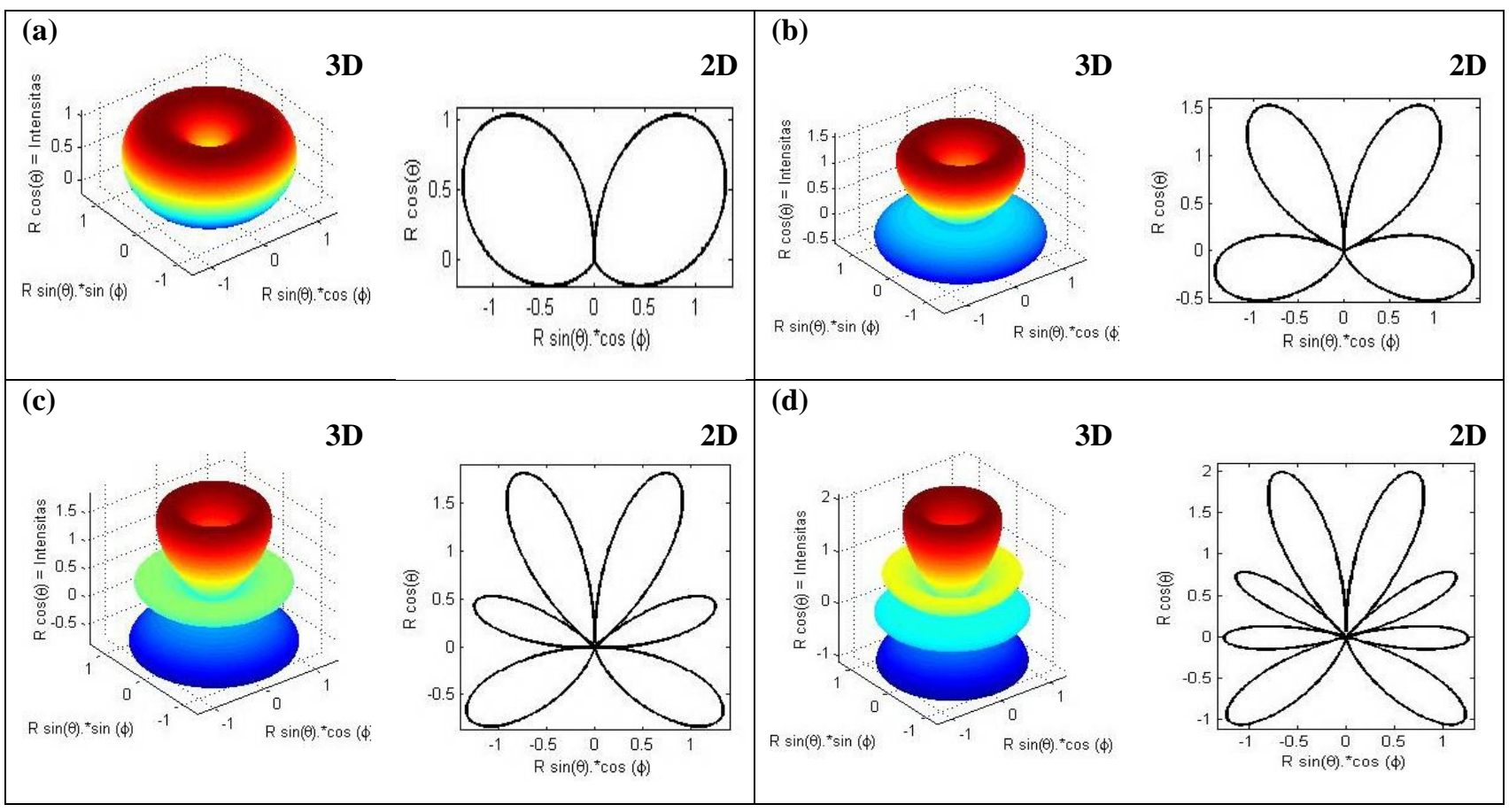

Gambar 1. Visualisasi Fungsi Gelombang Sudut Potensial Eckart plus Scarf dalam Koordinat Bola Terhadap Perubahan Bilangan Kuantum Sudut $n_{l}(\mathrm{a}) G_{0122}$, (b) $G_{1122}$ (c) $G_{2122}$ dan (d) $G_{3122}$ 

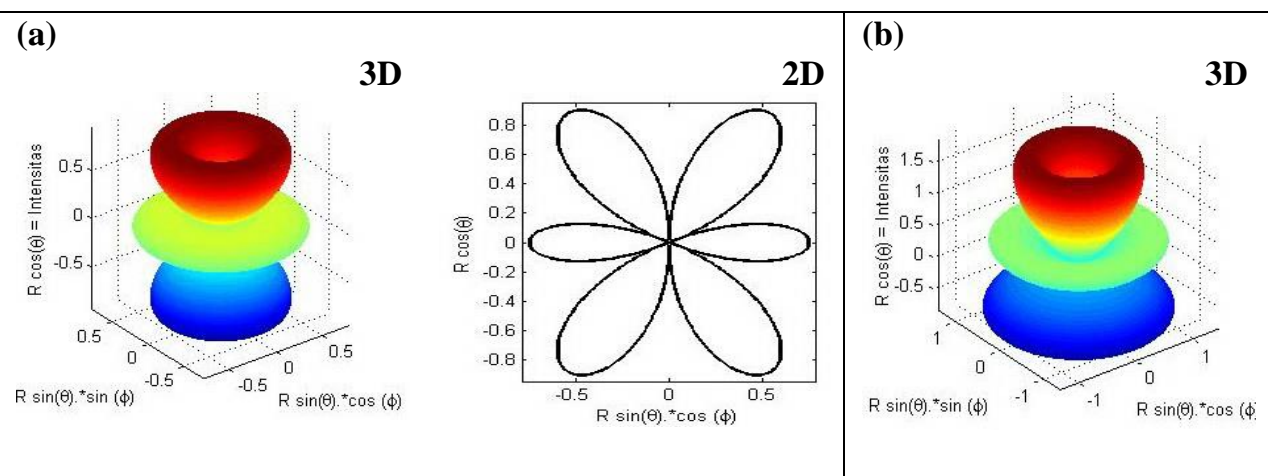

3D
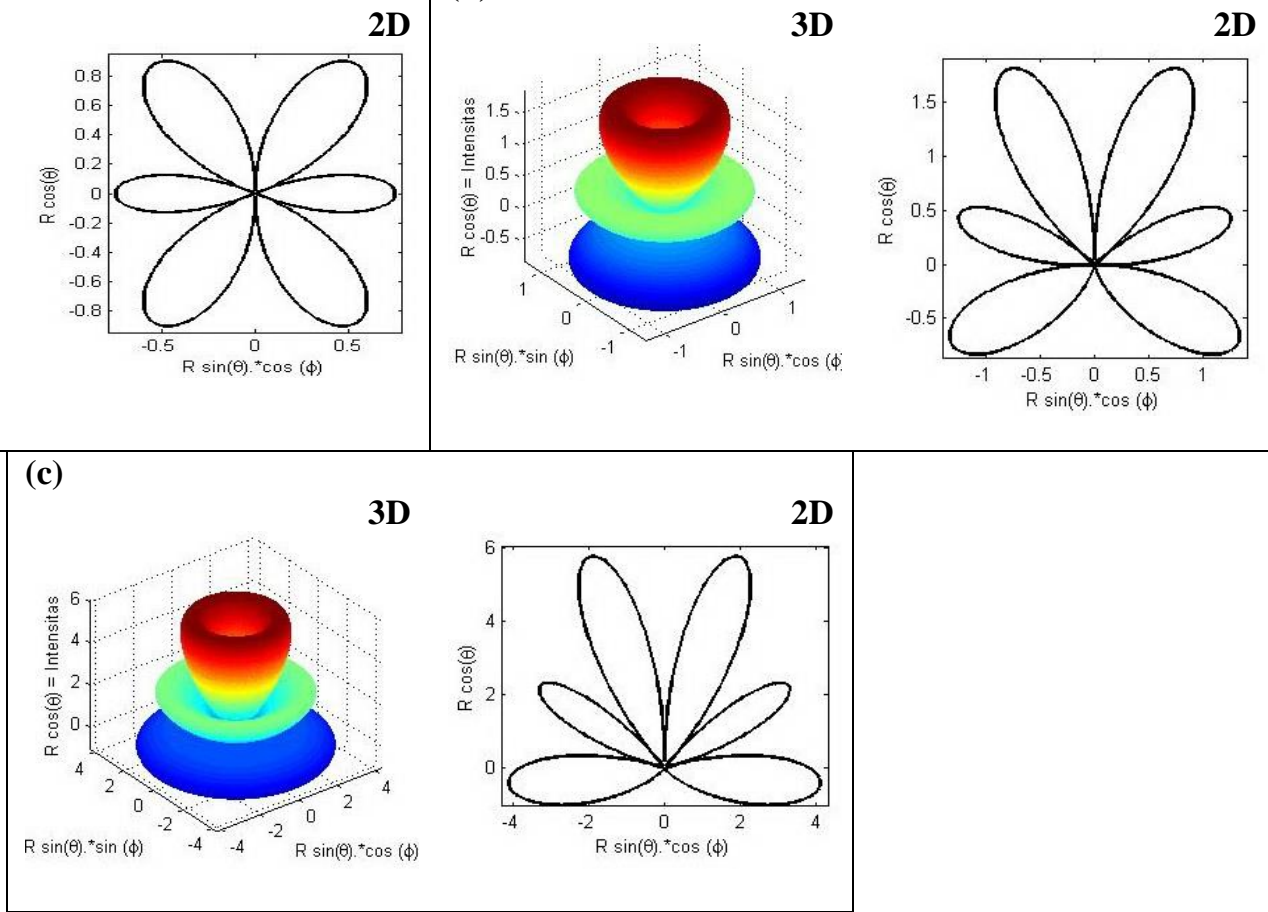

Gambar 2. Visualisasi Fungsi Gelombang Sudut Potensial Eckart plus Scarf dalam Koordinat Bola Terhadap Perubahan parameter potensial (a) $G_{2100}$ (b) $G_{2122}$ dan (c) $G_{2144}$

Berdasarkan Gambar 1, dapat diketahui bahwa dengan peningkatan bilangan kuantum sudut $n_{l}$, maka semakin banyak fungsi gelombang yang dihasilkan pada interval yang sama. Kondisi ini menunjukkan bahwa fungsi gelombang sudut engalami degenerasi. Selain itu, dengan meningkatnya bilangan kuantum sudut $n_{l}$, maka posisi ditemukannya partikel semakin jelas pada interval tertentu.

Berdasar Tabel 2, selanjutnya dilakukan visualisasi gelombang sudut menggunakan software Matlab 2013, diperoleh visualisasi pada Gambar 2. Berdasarkan Gambar 2 dapat diketahui adanya peningkatan amplitodo gelombang ketika parameter dalam potensial Scarf semakin meningkat. Peningkatan amplitudo menyatakan terdapat peningkatan energi sehingga partikel menempati sub kulit atom yang lebih besar, dimana sub kulit atom dipengaruhi oleh bilangan kuantum orbital.

\section{SIMPULAN}

Berdasar hasil analisis dan visualisasi dengan software Matlab 2013 diketahui bahwa perubahan bilangan kuantum mengakibatkan perubahan banyak gelombang yang dihasilkan, dan peningkatan nilai parameter pada potensial Scarf, mengakibatkan peningkatan amplitude sehingga energi semakin besar.

\section{UCAPAN TERIMA KASIH}

Terima kasih untuk Universitas Palangka, Kemenristek Dikti atas bantuan yang telah diberikan kepada penulis.

\section{REFERENSI}

[1]. Siregar,R.E. 2010. Fisika Kuantum. Penerbit: Widya Padjadjaran Bandung.

[2]. Hassanabadi, H., Lu, L.L., Zarrinkamar, S., Liu, G.H., Rahimov, H. 2012. Approximate Solutions of Schrodinger Equation under Manning_Rosen Potential in Arbitrary Dimension via susyqm. Acta Phys. Pol. A Vol.122 no.4.

[3]. Deta, U.A. Suparmi and Cari. 2013. Approximate Solution of Schrödinger Equation in D-Dimensions for Scarf Hyperbolic Potential Using Nikiforov-Uvarov Method. Adv. Studies Theor. Phys., Vol. 7, no. 13, $647-656$.

[4]. Greiner, W. 2000. Relativistic Quantum Mechanics. Berlin: Springer. 4.

[5]. Suparmi. 2011. Mekanika Kuantum II. Surakarta : FMIPA UNS.

[6]. Dong, S.H.2011. Wave Equations in Higher Dimensions. Heidelberg London New York : Springer.

[7]. Ikhdair, S.M and Sever, R. 2008. Approximate 1-state solutions of the D-dimensional Schrodinger equation for Manning-Rosen potential. Journal of Quantum Physics 08013518 Vol.1.

[8]. Vahidi, V, and Gourdarzi, H. 2011. Supersymmetric Approach for Eckart Potential Using the NU Method. Adv. Studies Theor. Phys., Vol. 5, no. 10, 469 - 476.

[9]. Castillo, Alvarez, and Kirchbach, Mariana. 2007. Exact Spectrum and Wave Functions of the Hyperbolic Scarf 
Potential in Terms of Finite Romanovski Polynomials. Revista Mexicana de Fi'Sica E53 (2) 143-154.

[10]. Tjolleng,A.2007. Pengantar Pemrograman Matlab, Elex Media Komputindo. Jakarta.

[11]. Ikhdair, S.M and Sever, R. 2007. Exact solutions of the modified Kratzer potential plus ring-shaped potential in the D-dimensional Schrodinger equation by the NikiforovUvarov method. Journal Of Quantum Physics 0703008 Vol.1.

[12]. Antia, A.D., Ikot, A.N., and Akpabio, L.E. 2010. Exact Solutions of The Schrödinger Equation with ManningRosen Potential Plus A Ring-Shaped Like Potential by Nikiforov-Uvarov Method. European Journal of Scientific Research, 46, 107-118. 